\title{
MAINTENANCE OF A HYBRID ZONE: THE ROLE OF FEMALE MATE CHOICE
}

\author{
Jane M. Hughes,,$^{1,4}$ Alicia Toon, ${ }^{1}$ Peter B. Mather, ${ }^{2}$ and Corinna L. Lange ${ }^{3}$ \\ ${ }^{1}$ Griffith School of Environment, Griffith University, Nathan Queensland, 4111, Australia; \\ ${ }^{2}$ Biogeosciences, Fast, Queensland University of Technology, Gardens Point, Queensland, 4001, Australia; and \\ ${ }^{3}$ School of Biological Sciences, University of Queensland, St Lucia, Queensland, 4072, Australia
}

\begin{abstract}
Hybrid zones between different plumage morphs are common in birds. These zones can be maintained by (1) divergent selection pressures on either side of the zone or (2) some restriction to mating between the forms that limits gene flow from one side to the other. In eastern Australia, there is a distinct hybrid zone between two plumage forms of the Australian Magpie (Cracticus tibicen), with black-backed birds in the north, white-backed birds in the south, and both forms plus intermediates in a zone $\sim 100 \mathrm{~km}$ wide. On the basis of social groups, there is no evidence of assortative mating in the hybrid zone. However, extrapair fertilizations (EPF) occur in other Australian Magpie populations and, thus, may also occur in the hybrid zone. We examined evidence of EPFs in the hybrid zone to test for either (1) positive assortative mating or (2) preference for the brighter plumage form. Although there were significant levels of EPFs of $\sim 30 \%$, there was no evidence for positive assortative mating or preference for the brighter white-backed males. Other explanations for the current distribution of the hybrid zone and its maintenance will need to be investigated. Received 3 February 2011, accepted 26 August 2011.
\end{abstract}

Key words: Australian Magpie, Cracticus tibicen, divergent selection, extrapair fertilization, hybrid zone, inbreeding avoidance, mate choice, positive assortative mating.

\section{Maintien d'une zone hybride : le rôle du choix du partenaire par la femelle}

RÉSUMÉ.-Les zones hybrides entre différents morphes de plumage sont courantes chez les oiseaux. Ces zones peuvent être maintenues par (1) des pressions sélectives divergentes de chaque côté de la zone ou (2) une certaine limitation de l'accouplement entre les formes qui restreint le flux de gènes d'un côté à l'autre de la zone. Dans l'est de l'Australie, il existe une zone hybride distincte entre deux formes de plumage de Cracticus tibicen, avec des oiseaux au dos noir dans le nord, des oiseaux au dos blanc dans le sud et les deux formes ainsi que des intermédiaires dans une zone large d'environ $100 \mathrm{~km}$. Sur la base des groupes sociaux, il n'existe aucune évidence d'homogamie dans la zone hybride. Cependant, des fertilisations extraconjugales (FEC) ont lieu dans d'autres populations australiennes de pies et, de ce fait, elles peuvent également se produire dans la zone hybride. Nous avons examiné les preuves de FEC dans la zone hybride afin de tester pour (1) l'homogamie positive ou (2) une préférence pour la forme de plumage la plus claire. Malgré les niveaux significatifs de FEC d'environ $30 \%$, il n'y avait aucune preuve d'homogamie positive ou de préférence pour les mâles au dos blanc plus clair. D'autres explications de la répartition actuelle de la zone hybride et de son maintien doivent être étudiées.

HYBRID ZONES AND their maintenance have been studied by evolutionary biologists for over a century (Harrison 1993). They can arise through secondary contact between previously allopatric populations (Hewitt 1988) or, alternatively, they can result from different selection pressures favoring alternative forms on either side of the zone (Barton and Hewitt 1985). These zones have been shown to be maintained by (1) divergent selection at opposite ends of the zone (Jiggins and Mallet 2000), (2) positive assortative mating within the zone (Brodin and Haas 2009), or (3) reduced fitness of hybrids (Barton and Hewitt 1985) due to genetic incompatibility (Price 2008) or intermediate behavior or appearance of hybrids that make them less attractive as partners (Bridle et al. 2006).
In birds, hybrid zones between various plumage forms are common in nature-for example, between Pied Flycatchers (Ficedula hypoleuca) and Collared Flycatchers (F. albicollis) (Veen et al. 2001), between Lazuli Buntings (Passerina amoena) and Indigo Buntings (P. cyanea) (Baker and Boylan 1999), and between forms of Australian Magpies (Cracticus tibicen) (Hughes 1982, Toon et al. 2003) - and recent studies suggest that mate choice may be important in maintaining these hybrid zones. For example, sexual imprinting, whereby young individuals learn specific characteristics of their parents that ensure that they choose mates with those characteristics, has been suggested to maintain a hybrid zone between Hooded Crows (Corvus cornix) and Carrion Crows (C. corone) in Europe (Haas et al. 2010). By contrast, preference of

${ }^{4}$ E-mail: jane.hughes@griffith.edu.au

The Auk, Vol.128, Number 4, pages 688-695. ISSN 0004-8038, electronic ISSN 1938-4254. @ 2011 by The American Ornithologists' Union. All rights reserved. Please direct all requests for permission to photocopy or reproduce article content through the University of California Press's Rights and Permissions website, http://www.ucpressjournals. com/reprintInfo.asp. DOI: 10.1525/auk.2011.11026 


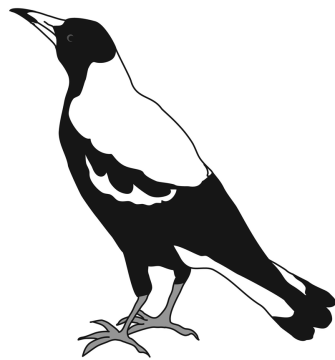

a

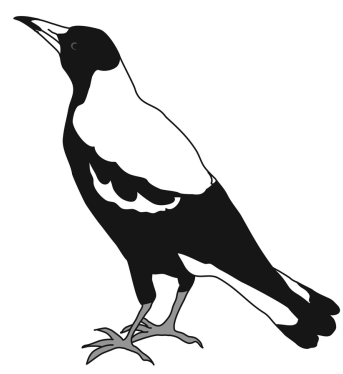

f

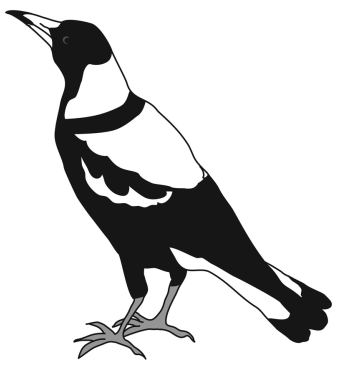

b

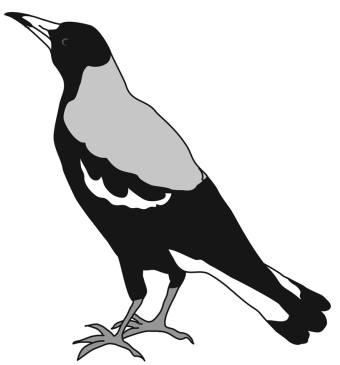

$\mathrm{g}$

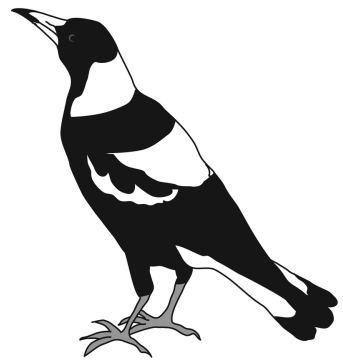

c

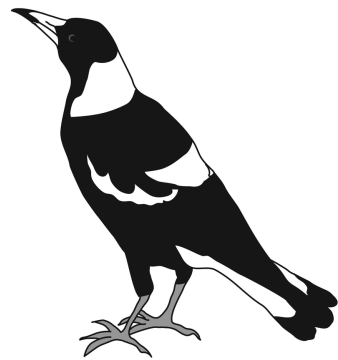

d

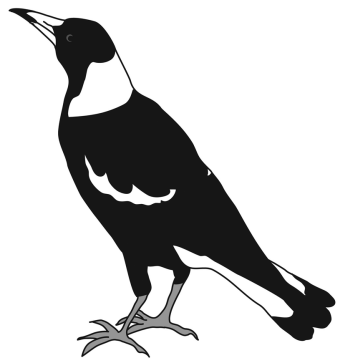

e

FIG. 1. Distribution and back-color patterns of the Australian Magpie. Panels A-E show variation in male birds. A is pure white back (=0) and $\mathrm{E}$ is pure black back (= 4). B, C, and D are intermediates, designated as 1, 2, and 3. Differences between (F) males and (G) females of the white-backed form are shown. Panel $\mathrm{H}$ shows the location of the hybrid zone in eastern Australia (striped) between black-back magpies in the north and white-back magpies in the south. The distribution of the Australian Magpie is shown in gray on the map of Australia (adapted from The Atlas of Australian Birds; Barrett et al. 2003).

female Black-capped Chickadees (Poecile atricapillus) and Carolina Chickadees (P. carolinensis) for Carolina-like males may be an important factor in the movement of this hybrid zone (Reudink et al. 2006). Habitat, in conjunction with mate choice, may also be important in maintaining hybrid zones by way of natural selection, such as in Golden-collared Manakins (Manacus vitellinus) and White-collared Manakins (M. candei), in which a balance between sexual selection for bright plumage and selection against conspicuousness in different habitats is proposed as contributing to stabilizing the hybrid zone (Uy and Stein 2007).

A factor that has complicated the assessment of the role of mate choice in maintaining hybrid zones in recent years is the fact that many socially monogamous birds have been shown to engage in extrapair copulations (EPCs; Griffith et al. 2002). Thus, assessing evidence for assortative mating by observing social groups may give misleading results because females may mate with males from outside their social pair or group. The few studies that have examined the patterns of EPCs or extrapair fertilizations (EPFs) within hybrid zones to determine whether females mated socially with a heterospecific male are more likely to engage in EPCs (i.e., whether there was evidence for positive assortative mating) have yielded mixed results. Positive assortative mating was found in flycatchers (Veen et al. 2001) but not in chickadees: female Black-capped and Carolina chickadees both preferred Black-capped males (Reudink et al. 2006).

The Australian Magpie (hereafter "magpie") is broadly distributed across Australia (Fig. 1), where it has been divided into a number of subspecies based mostly on plumage and bill morphology (Schodde and Mason 1999). In eastern mainland Australia, there are three recognized subspecies, but the major difference occurs in back color (Fig. 1). Cracticus t. tyrannica occurs in southern Victoria. Males of this subspecies have pure white backs and females have pale gray backs. In the remaining eastern mainland, there are two subspecies, C.t.tibicen and C. t. terraereginae, which differ from each other only in very minor morphological characteristics (Schodde and Mason 1999). In both of these subspecies, both sexes have a black saddle across the back, the only difference between the sexes being that males and females have white and pale gray napes, respectively. In the hybrid zone, intermediate forms and both parental types co-occur. Intermediates have varying widths of the black saddle, from a couple of back feathers to an almost complete covering of the back (Fig. 1). The hybrid zone is narrow ( $100 \mathrm{~km}$; see Fig. 1) in relation to the distribution of parental types (Burton and Martin 1976). In southeast Australia, including the hybrid zone, magpies live in permanent territorial groups that range in size from 3 to 15 birds (Hughes et al. 1996). A territory usually consists of a dominant male and female and subordinate adults and juveniles that have fledged in previous years within the territory, although new birds also occasionally join a territory as either an adult or a juvenile. Observational studies suggest that one or more females (up to five) will build separate nests within a territory, with the dominant females being the first to nest each year (Carrick 1972, Hughes et al. 1996). Paired males will feed nesting females, but helping behavior by other members of the group includes only the feeding of nestlings 
and fledglings (Hughes et al. 1996). Occasionally, adults of both sexes feed young at more than one nest, and nestlings are sometimes fed by multiple adult males and females. In the hybrid zone, social groups consist of all combinations of white-backed, blackbacked, and intermediate forms (Hughes et al. 2002).

Studies of neutral markers, mitochondrial DNA variation (Hughes et al. 2001), and microsatellite variation (Toon et al. 2007) across this hybrid zone show no evidence of restricted gene flow or structure, and there is no relationship between mitochondrial haplotype or microsatellite alleles and plumage pattern. Hughes et al. (2001) proposed that divergent selection on either side of the hybrid zone was the most likely mechanism to explain its maintenance and proposed that vegetation cover and mate choice may be involved. The habitat of most black-backed birds is relatively open, whereas white-backed birds typically inhabit more heavily wooded areas. Hughes et al. (2001) proposed that natural selection through predation on nestlings and fledglings may favor black backs in open areas, whereas the advantages of obscurity may be less important in heavily wooded areas. A further suggestion was that the white-backed form is very conspicuous, particularly in the ultraviolet (UV) range. Although UV reflectance may be at a disadvantage as a result of predation in more open habitat, it may be favored by sexual selection, either by being better able to hold territories, which are critical for magpie breeding (Carrick 1972), or by being more attractive to females (e.g., Pearn et al. 2003). Consequently, the hybrid zone may be maintained by mate choice favoring white-backed males over black-backed males and selecting against the offspring of white-back males in open areas.

An earlier study examined some of these hypotheses within the hybrid zone (Hughes et al. 2002) and showed that territories with nests located in forest produced more fledglings than territories with nests in isolated trees and that in forested areas, territories with white-backed males produced more fledglings than blackbacked males, with the result reversed in open areas. There was, however, no evidence that white-backed males were more likely to hold territories, hold bigger territories, or have more females within a territory, despite the fact that resident magpies were more aggressive toward a white-backed intruder (Kallioinen et al. 1995). From observations of social groupings, Hughes et al. (2002) showed that females did not prefer white-backed males over other males as had been predicted, nor was there any evidence of positive assortative mating, which is another mechanism that is suggested to maintain hybrid zones in other birds (e.g., crows; Haas et al. 2010).

A factor that may complicate interpretation is the observation that magpies show high levels of extrapair matings. In a western Australian population, $83 \%$ of fledglings were fathered by males from outside the territory (extra-group fertilization [EGF]; Hughes et al. 2003), whereas $44 \%$ of fledglings from a population of whitebacks in eastern Australia were fathered from outside the territory (Durrant and Hughes 2005). There were no obvious correlates with EGFs in the white-backed population, although inbreeding avoidance was suggested as a possible reason. Unlike most birds, in magpies, females are the philopatric sex (Veltman and Carrick 1990) and, therefore, where multiple females breed within a territory they are likely to be closely related to the other adults in the territory. These findings suggest the possibility that magpies in the hybrid zone may also exhibit high levels of EPF and, if so, previous conclusions concerning lack of assortative mating and lack of preference for whitebacked males based on social pairing may have been in error.
Given the likelihood of EPFs in the hybrid zone, we aimed to test the hypotheses that (1) EPFs are more common when the social partner is intermediate or black-backed or (2) EPFs would be more common when the social partner has a different back color than his partner. The former would suggest evidence for sexual selection for bright white plumage (contributing to divergent selection), whereas the latter would provide evidence that the hybrid zone was maintained by positive assortative mating. Additionally, we predicted (3) that EPFs are an inbreeding avoidance strategy that occurs when the social mates are closely related, as has been suggested by Durrant and Hughes (2005).

\section{Methods}

Study site and field methods.-Between 1992 and 2005, field data and blood samples were collected from a population of magpies in southeastern Australia. The study site, on Lambing Gully Road, Victoria (center of study site: $36^{\circ} 58^{\prime} 18.31^{\prime \prime} \mathrm{S}, 145^{\circ} 13^{\prime} 37.76^{\prime \prime} \mathrm{E}$ ), was selected in the hybrid zone between northern black-backed and southern white-backed magpies. Nineteen territories were selected because of their complete sample history and records throughout the study: A, AH, ARV, BS, CS, DII, EH, GC, LSL, MP, OB, PS, PSF, QNQ, SGC, SGC04, TN, TYO, and UD. All territories selected had nests in forest and had between $20 \%$ and $50 \%$ tree coverage in their territory. The territories were not contiguous; rather, they were located on either side of the road $(\sim 11 \mathrm{~km})$. All magpies in the study $(n=338)$ were captured using a wire trap baited with grated cheese. Young birds were captured soon after fledging. It was not possible to sample them while still in the nest because magpies nest very high in tall eucalypt (Eucalyptus spp.) trees. They were bled from the toenail and individually color-banded with powder-coated stainless steel bands according to the requirements of the Australian Bird and Bat Banding Scheme. Blood samples were stored in tissue lysis buffer until returned to the laboratory, where they were stored at $-80^{\circ} \mathrm{C}$.

Field observations.-Territory membership was determined by field observation during three study periods each year. Following banding of all birds in a territory in the previous season, territories were observed for a 1-week period in September, while nests were being attended; a 4-week period in November following fledging of young from nests; and finally a 1-week period in March to establish survival of fledged young. Presence in a territory required that a bird be observed within the territory boundaries on three separate watches ( 20 min territory $\left.^{-1}\right)$ during each study period, a method similar to that used in other studies of magpie parentage (i.e., Hughes et al. 2002, Durrant and Hughes 2005). The sex and back color of every member of a territory were determined both while in the hand and by observation through a telescope. Back color for each bird was scored following Hughes et al. (2002): pure white-backed birds were given a 0 , pure black-backed birds were given a 4 , and intermediates were scored 1-3 depending on the proportion of black band on their backs (Fig. 1). Back color can easily be determined in fledglings because those sections of the back that will eventually be white are pale gray, whereas those that will be black are dark gray.

Microsatellite analysis.-Eight microsatellite loci were selected from a library developed at Griffith University specifically for the magpie: Gt43a, Gt115b, Gt115a, Gt112a, Gt67c, Gt201a, Gt206b (Hughes et al. 2003), and Gt208 (Durrant and Hughes 2005). Total genomic DNA was isolated from whole blood using standard phenol-chloroform procedures 
(Baker et al. 2000). Polymerase chain reaction (PCR) amplification of microsatellites for each primer set was carried out in $12.5-\mu \mathrm{L}$ reactions containing $1.25 \mu \mathrm{L}$ of $10 \times$ Taq polymerase buffer, $2 \mathrm{mM}$ magnesium chloride, $0.2 \mathrm{mM}$ of dNTPs, $0.4 \mu \mathrm{M}$ of forward and reverse primers, $0.25 \mathrm{U}$ of Biotech Taq polymerase, and 50-100 ng of DNA template. For all microsatellite loci, an initial 3 -min $94^{\circ} \mathrm{C}$ denature cycle was followed by 30 cycles of $94^{\circ} \mathrm{C}$ for $30 \mathrm{~s}$, annealing temperature for $30 \mathrm{~s}$ and $72^{\circ} \mathrm{C}$ for $30 \mathrm{~s}$, followed by an additional extension step of $72^{\circ} \mathrm{C}$ for $7 \mathrm{~min}$. Annealing temperatures followed those outlined in Hughes et al. (2003) and Durrant and Hughes (2005).

Microsatellite product was mixed with $12.5 \mu \mathrm{L}$ of deinonized formamide and denatured at $95^{\circ} \mathrm{C}$ for $5 \mathrm{~min}$ and cooled immediately on ice before being loaded onto $5 \%$ polyacrylamide gels on a Gelscan 2000 Genetic Analyser (Corbett Research, Mortlake, Australia). A commercial standard was used to size products across and among gels (ABI PRISM Tamra 350). Additionally, a homemade size standard of pooled product from several individuals was used to ensure reproducibility of results.

All birds were genetically sexed following methods developed by Griffiths et al. (1996). This method is PCR based and designed to amplify homologous fragments of the CHD-Z and CHD-W genes with two primers (P2 and P8). The target fragments were amplified with 30 cycles of the following program: $94^{\circ} \mathrm{C}$ for $30 \mathrm{~s}, 54.5^{\circ} \mathrm{C}$ for $30 \mathrm{~s}$, and $72^{\circ} \mathrm{C}$ for $30 \mathrm{~s}$. The amplified product was electrophoresed through a $3 \%$ agarose gel in $0.5 \times$ TBE buffer and the bands were visualized under a UV light. Females were identified by having two bands (ZW) and the homogametic males as having a single band (ZZ).

Statistical analysis.-Allele frequencies, expected and observed heterozygosities, and exact tests for deviation from HardyWeinberg equilibrium were calculated in GENEPOP (Raymond and Rousset 1995) to check for null alleles and test for inbreeding. Exclusion probabilities for female parent only $\left(P_{\text {EXC }}{ }^{1}\right)$ and male parent when female parent is assigned $\left(P_{\text {EXC }}{ }^{2}\right)$ were calculated for each locus following Jamieson (1994).

All adults ( $>2$ years) present in a territory during a breeding season were considered as potential parents for juveniles fledged in that territory during that breeding season. We calculated two indices of parentage. First, we assigned within-pair fertilization (WPF) when a territorial female and dominant territorial male were assigned as parents and EPF when offspring were not sired by the dominant male in the territory. Second, we assigned within-group fertilization (WGF) when a territorial female and any territorial male were assigned parentage and EGF when offspring were not sired by any adult male in the group. Parentage was assigned with CERVUS (Marshall et al. 1998), allowing one possible mismatch due to genotyping error, mutation, or the presence of null alleles. We assumed that $75 \%$ of candidate parents had been sampled, and typing error was set at 0.01 . Maternity was assigned first, followed by attempts to assign paternity from males within the territory during the breeding season. For those offspring assigned to more than one maternal or paternal parent, the log-likelihood ratio (LOD scores) or combined LOD scores were used to assign the most likely parents.

We tested for a relationship between back color of dominant male in the territory and EPF in two ways. First, each fledging was used as a data point and a contingency table was set up to examine the relationship between back color of the dominant male and whether or not he was cuckolded. Second, we used each territory as a data point (except where the dominant male changed during the study, which occurred in eight territories) and calculated the proportion of times the dominant male was cuckolded. We used a Spearman's rank correlation to test for a positive correlation between back color (ranging from 0 for pure white backs to 4 for pure black backs) and percent EPF. We also compared EPF between magpie pairs of the same and different back colors using chi-square tests to test for positive assortative mating.

We tested for a relationship between the number of helpers in a territory and the proportion of extrapair offspring in each territory. Helpers were defined as the average number of adult birds ( $>2$ years), excluding the parental birds within each territory. The numbers of EPFs and WPFs were tabulated for each territory with helpers ranging from 2 to $\geq 7$ for total helpers and 1 to $\geq 5$ for male helpers and female helpers. Spearman's rank correlation coefficient $(\rho)$ was used to identify and test for significant relationships between the number of EPF and the number of helpers.

An index of relatedness $(r)$ between individuals within territories was calculated in KINSHIP, version 1.3.1 (Queller and Goodnight 1989). We tested for a relationship between the relatedness of the dominant male and his social partner and the proportion of EPFs using a Mann-Whitney $U$ test.

\section{RESULTS}

Demographics and parentage assignment.-We captured 212 juveniles within the 19 territories between 1995 and 2005. Some territories changed in number of adults each year and ranged from 2 to 11 adults over the period of study (mean in the year $2000=5.6$ ). The total number of adults analyzed for parentage was 174, which comprised 103 females and 71 males, of which 48 had been captured as juveniles during the study. Female back-color distributions, classified on a scale of 0 to 4 , were $17,12,15,26$, and 33 , respectively, whereas for males the distribution was $13,3,9,23$, and 23, respectively. Six offspring were excluded from the analysis because sampling of territorial adults in that year was incomplete, and one other was excluded after extraction of low-quality DNA template $(n=205$ usable offspring). Of these, 137 were assigned to maternal and paternal parents within the territory from which they fledged (= WGF) and 54 were assigned to a maternal parent but no paternal parent within their territory (= EGF). WPFs accounted for 118 offspring (i.e., maternal parent and the dominant male). The difference between WGF and WPF suggests that only 19 of 205 offspring (9.3\%) were sired by nondominant territorial males mating with territorial females, compared with 118 of 205 young (57.6\%) that were sired by the dominant territorial male and a territorial female. Six offspring were assigned to within-group males but not within-group female parents, which suggests intraspecific brood parasitism, and eight offspring were unassigned. Within territories, the proportion of offspring that resulted from EPFs ranged from $0 \%$ to $69.2 \%$. Under the parameters we selected for CERVUS, 37 offspring were assigned to a resident female with a mismatch present and 29 offspring were assigned to a resident male with a mismatch. These mismatches represented $2.4 \%$ of bands scored as a result of typing error or mutation or a combination of the two.

The number of alleles and observed and expected heterozygosities for microsatellites are given in Table 1. Hardy-Weinberg exact tests were conducted on a subset of the data using only adults banded in territories in 2000 to avoid including family groups. No loci deviated from HWE after Bonferroni correction. Exclusion probabilities per locus were moderate with no parent 
TABLE 1. Characteristics of microsatellite loci used for parentage analysis in a population of Australian Magpies in the hybrid zone in southeastern Australia sampled between 1992 and $2005\left(H_{\mathrm{O}}=\right.$ observed heterozygosity, $H_{\mathrm{E}}=$ expected heterozygosity, $P_{\mathrm{EXC}}{ }^{1}=$ exclusion probability for first parent assigned, $P_{\mathrm{EXC}}{ }^{2}=$ exclusion probability when both parents are assigned, and $F_{\mathrm{IS}}=$ inbreeding coefficient; ${ }^{* *} P<0.01,{ }^{*} P<0.05$ ).

\begin{tabular}{lcccccr}
\hline Locus & $\begin{array}{c}\text { Number of } \\
\text { alleles }\end{array}$ & $H_{\mathrm{O}}$ & \multicolumn{1}{c}{$H_{\mathrm{E}}$} & $P_{\mathrm{EXC}}{ }^{1}$ & $P_{\mathrm{EXC}}{ }^{2}$ & \multicolumn{1}{c}{$F_{\mathrm{IS}}$} \\
\hline Gt43a & 20 & 0.844 & 0.884 & 0.622 & 0.767 & 0.015 \\
Gt115b & 17 & 0.799 & 0.87 & 0.586 & 0.74 & -0.005 \\
Gt115a & 19 & 0.716 & 0.748 & 0.366 & 0.544 & 0.095 \\
Gt112 & 24 & 0.907 & 0.931 & 0.752 & 0.859 & 0.006 \\
Gt67c & 6 & 0.451 & 0.461 & 0.111 & 0.258 & 0.008 \\
Gt201a & 17 & 0.749 & 0.768 & 0.407 & 0.588 & -0.005 \\
Gt206b & 16 & 0.803 & 0.829 & 0.496 & 0.665 & -0.043 \\
Gt208 & 18 & 0.818 & 0.814 & 0.493 & 0.667 & -0.063 \\
Total & 6 to 24 & & & 0.997 & 0.999 & \\
\hline
\end{tabular}

assigned (0.366-0.752) and high with maternal parent assigned (0.544-0.859). Exclusion probabilities for the combined eight loci were 0.997 and 0.999 , respectively.

Extrapair fertilizations and back color--There was a significant relationship ( $\left.\chi^{2}=10.3, \mathrm{df}=4, P<0.04\right)$ between the probability of a juvenile being fathered by an outside male and the back color of the dominant male of the territory (Fig. 2); thus, EPFs were not random with respect to back color of the dominant male. This relationship was not significant $\left(\chi^{2}=2.2, \mathrm{df}=2, P=0.34\right)$ when all intermediate back-color forms were pooled. No general pattern was noted for the different back-color groups, and the significant result was due to the high incidence of EPF for offspring when the dominant male had a back color of 1 (M1). This is, in a sense, pseudoreplicated because each offspring was regarded as a data point, with multiple offspring from a single territory. When the analysis was redone and the proportion of offspring from EPF was estimated using each of the territories as a single data point (unless the dominant male changed), there was no significant relationship $(\rho=-0.04, P=0.82)$ between back color of the male and level of EPF. The initial impression of an increased proportion of EPF in territories with M1s was caused by one territory with one $\mathrm{M} 1$ that had a particularly high level of EPF.

The analysis of the relationship between proportion of EPF and social partner with the same or a different plumage form (Fig. 3) was nonsignificant $\left(\chi^{2}=0.001, \mathrm{df}=1, P=0.97\right)$. The relationship was also nonsignificant $\left(\chi^{2}=0.014, \mathrm{df}=1, P=0.91\right)$ when intermediates were pooled as one plumage form (i.e., any intermediate mating with an intermediate was considered as mating within the same plumage form). In other words, there was neither positive nor negative assortative mating.

Helpers, relatedness, and extrapair fertilizations.-The total number of helpers was correlated significantly with the proportion of EPFs ( $\rho=0.89, P=0.019)$. The proportion of EPFs also increased as the number of female helpers increased $(\rho=0.94$, $P=0.005$; Fig. 4). The number of male helpers showed a positive trend with increasing helper numbers, although the relationship was not significant ( $\rho=0.7, P=0.19$ ). There was no relationship between relatedness of a female and her social partner and the likelihood that she would cuckold him $(z=-0.686, P=0.25)$.

Despite the fact that there appeared to be no clear relationship between the probability of EPFs and plumage or relatedness

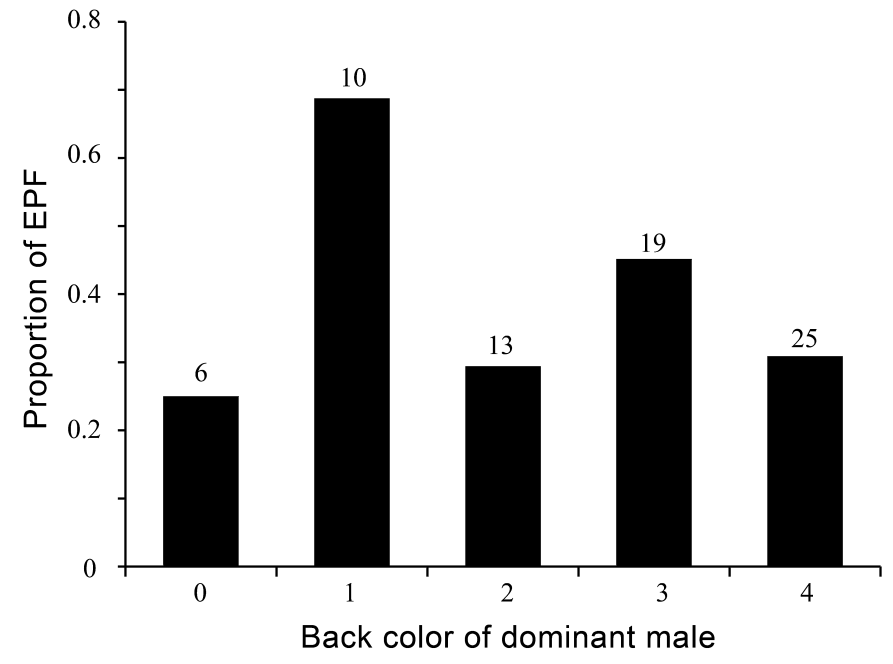

FIG. 2. The relationship between back color of dominant male Australian Magpies (sampled in 1992-2005) and extrapair fertilization (EPF) in the hybrid zone in southeastern Australia. Bars represent proportion of young resulting from EPFs for each class of back color of the dominant male $(0$ is white-backed and 4 is black-backed; $1-3$ are intermediate back color). Numbers above bars indicate the number of young resulting from EPFs within the study period.

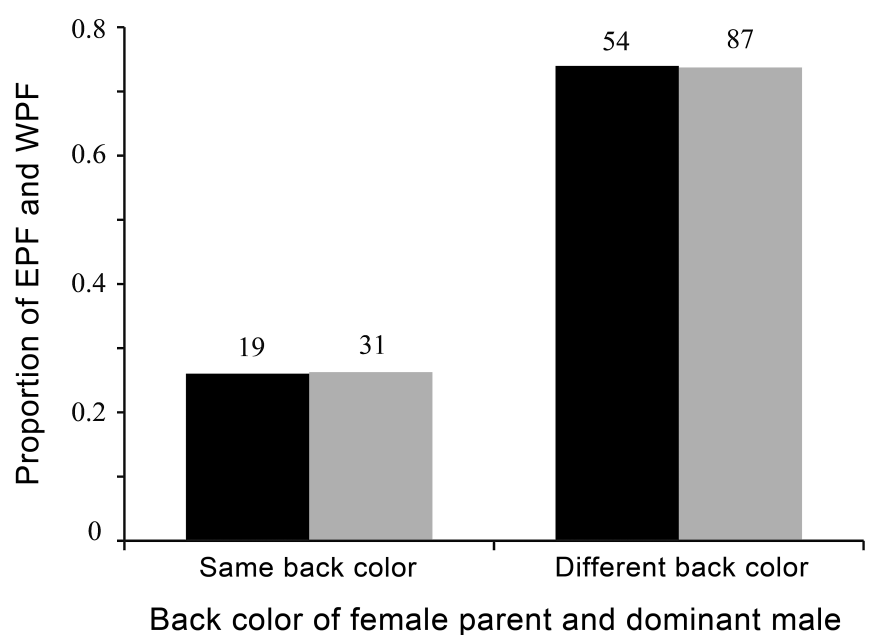

FIG. 3. The relationship between the back color of social partners and extrapair fertilization (EPF) in a population of Australian Magpies (sampled in 1992-2005) in the hybrid zone in southeastern Australia. Bars represent the proportion of EPF (black) and within-pair fertilization (WPF; gray) for social partners within the same back-color class or within different backcolor classes. Five back-color classes were used ( 0 is white-backed and 4 is black-backed; 1-3 are intermediate back color). Numbers of EPFs and WPFs for the same back color of social partners and for different back color of social partners are shown above bars.

between social partners, variation among territories in the percentage of offspring fathered by outside males was high. For example, in one territory (TN), all four (100\%) offspring that fledged during the study period resulted from EPFs, whereas in two other territories (UD, EH), only 1 of $13(<8 \%)$ and 0 of $4(0 \%)$ were fathered by an outside male over this same period (Table 2 ). 
TABLE 2. Assigned parentage for 205 Australian Magpie offspring from 19 territories, sampled from a population in the hybrid zone in southeastern Australia between 1992 and 2005. Numbers of offspring resulting from within-pair fertilization (WPF) and extrapair fertilization (EPF) are shown for each territory.

\begin{tabular}{lcllrrrr}
\hline Territory & $\begin{array}{c}\text { Number of } \\
\text { juveniles }\end{array}$ & $\begin{array}{c}\text { Mean } \\
\text { number } \\
\text { of females }\end{array}$ & $\begin{array}{c}\text { Mean } \\
\text { number of } \\
\text { males }\end{array}$ & WPF & EPF & $\begin{array}{c}\text { Paternal } \\
\text { parent } \\
\text { assigned }\end{array}$ & $\begin{array}{c}\text { No parents } \\
\text { assigned }\end{array}$ \\
\hline A & 8 & 2.33 & 2.17 & 4 & 4 & 0 & 0 \\
AH & 11 & 3.33 & 2.78 & 9 & 2 & 0 & 0 \\
ARV & 7 & 3.33 & 1.33 & 6 & 1 & 0 & 0 \\
BS & 3 & 3.5 & 2 & 1 & 1 & 1 & 0 \\
CS & 9 & 2.33 & 1.83 & 5 & 4 & 0 & 0 \\
DII & 6 & 3 & 1.33 & 3 & 3 & 0 & 0 \\
EH & 4 & 3 & 2 & 4 & 0 & 0 & 0 \\
GC & 11 & 2.42 & 1.43 & 9 & 1 & 0 & 1 \\
LSL & 9 & 2.8 & 1.2 & 8 & 1 & 0 & 0 \\
MP & 24 & 3 & 1.78 & 15 & 8 & 0 & 1 \\
OB & 18 & 3.9 & 2.7 & 5 & 11 & 0 & 2 \\
PS & 21 & 3.89 & 2.67 & 13 & 8 & 0 & 0 \\
PSF & 7 & 2.75 & 5 & 3 & 2 & 0 & 2 \\
QNQ & 9 & 2 & 2 & 6 & 2 & 1 & 0 \\
SGC & 19 & 3 & 1.2 & 11 & 7 & 0 & 1 \\
SGC04 & 3 & 2.5 & 2 & 0 & 2 & 1 & 0 \\
TN & 4 & 2.33 & 2.67 & 0 & 4 & 0 & 0 \\
TYO & 19 & 3 & 3 & 4 & 11 & 3 & 1 \\
UD & 13 & 2.63 & 1.38 & 12 & 1 & 0 & 0 \\
Totals & 205 & & & 118 & 73 & 6 & 8 \\
\hline
\end{tabular}

\section{Discussion}

Magpies in the hybrid zone bred regularly outside their pair bond (26\% were EGFs and $36 \%$ were EPFs) but at lower rates than has been recorded elsewhere $(88 \%$ and $44 \%$ EGFs in a Western Australian population [Hughes et al. 2003] and in a purely white-backed population [Durrant and Hughes 2005], respectively). However, there was wide variation in the occurrence of EPFs in our study, with some

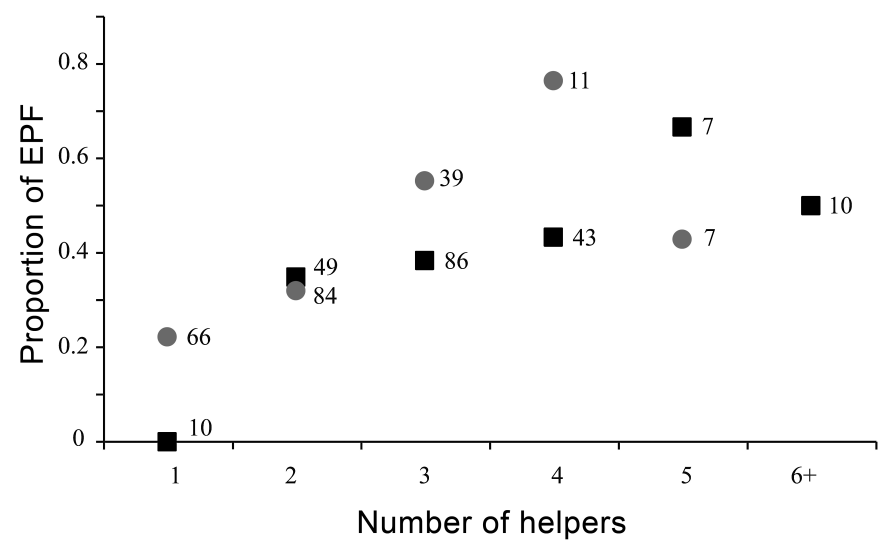

FIG. 4. The relationship between the number of helpers within a territory and the proportion of extrapair fertilizations (EPFs) in a population of Australian Magpies (sampled in 1992-2005) in the hybrid zone in southeastern Australia. Points represent the proportion of EPFs within each class of helpers. The numbers on the $x$-axis represent number of helpers within a territory within a period when the dominant male did not change. Proportions of EPFs in each class of male helpers are indicated by circles and those in females by squares. Total number of offspring within each helper class is shown next to the points. territories having very few or no offspring assigned as resulting from EPFs and one territory having all offspring assigned to EPFs.

Our primary goal was to test two hypotheses concerning mate choice in the magpie hybrid zone. Because we often could not identify the father (e.g., if he had come from an unsampled territory), we did this by examining whether there was a relationship between the probability of a male magpie being cuckolded and his plumage pattern. Our hypotheses were (1) that the brightest males would be less likely to be cuckolded or (2) that the males that did not match the plumage of their partner would be more likely to be cuckolded. Either of these outcomes would help explain the maintenance of the hybrid zone in southeastern Australia. The first would result if the hybrid zone was produced by different selection pressures north and south of the zone. As Hughes et al. (2001) suggested, black-backed birds would be favored north of the zone because they and their nests would be less conspicuous to predators than white-backed birds in the largely open habitats found there. Conversely, white-backed birds would be favored in the more forested south because, although they were more likely to attract predators, this was outweighed in their heavily wooded habitat by their mating advantage. Brightly colored males may be chosen because brightness is directly environmentally induced (low parasite load, good territory, etc.; Roulin 2004), because brightly colored males are intrinsically superior (good genes; Reudink et al. 2006, Pryke and Griffith 2007), or both. Furthermore, Galeotti et al.'s (2003) review concluded that much color polymorphism evolved under selective pressures linked to detectibility affected by different light environments, with the selective agents being prey, predators, or competitors.

Support for the second hypothesis would suggest that the hybrid zone is maintained by birds choosing to mate more often with others of the same or similar plumage pattern, as suggested 
for Carrion and Hooded crows (Haas et al. 2010) and Lazuli and Indigo buntings (Baker and Boylan 1999).

Both hypotheses were rejected because there was no significant relationship between back color and the probability of being cuckolded, despite the appearance of a significant statistical relationship driven by one male (back color M1). The only factor that was clearly related to the probability of EPFs in a territory was the number of female helpers. Magpie territorial groups are usually initiated by a small group of two to five birds, either from neighboring territories or from the nonterritorial flock (Carrick 1972). Once the group has established a territory, it is very rare for new birds to come from outside. In other words, almost all of those that were not in the initial group were fledged there. From our observations in the study area, new adult magpies move into a territory only when there are no longer any of that sex remaining or when the remaining bird is very old. Thus, in most cases, female helpers in the territory are daughters of the dominant pair and, hence, if the mother has mated with the dominant male (i.e., not an EPF), the helpers would be the daughters of the dominant male. Mating with an outside male thus avoids inbreeding and its potential genetic disadvantages (Keller and Waller 2002). Thus, social and sexual mate choice associated with back color may be random and EPF may be related to other intra-territorial relationships.

We tested the hypothesis that females would be more likely to mate with extrapair males if the dominant male was a close relative. By following territorial groups from 1992 through 2009, we know that some are composed of apparently very closely related birds. For example, one territory consists of males and females all fledged in the same territory, adjacent to their current territory (J. M. Hughes unpubl. data). Another territory included two adult females and a single male that had fledged in the same territory and took over after the dominant male disappeared. Contrary to expectations, there was no evidence for any relationship between relatedness and probability of EPFs. Females were not more or less likely to cuckold the dominant male if they were closely related to him.

Nevertheless, there were clear differences among territories, with some females consistently mating with the dominant male and others consistently mating with outside males, regardless of his plumage pattern or relatedness to the female breeder. Other factors associated with male fitness may be important, although a study of a pure white-backed population that attempted to estimate other components of fitness, such as male weight and internal and external parasite load, also found no relationship with the proportion of EGFs (Durrant and Hughes 2006).

Our initial goal was to explain the maintenance of the hybrid zone between white-backed and black-backed magpies in southeastern Australia. In previous molecular work, we had demonstrated that neither mitochondrial (Hughes et al. 2001) nor nuclear microsatellites (Toon et al. 2007) showed any differences across this hybrid zone. We were thus able to reject the notion that the zone could be merely the result of historical separation followed by secondary contact. Even if there had been historical separation north and south, the lack of genetic differentiation at neutral markers strongly implies that the differences in back color must be maintained by some form of natural selection related to the environment, balanced by asymmetrical mate choice or some form of positive assortative mating. The results of the present study rejected both hypotheses. Female magpies were not more likely to engage in EPF if their partner had a black or intermediate back color. Furthermore, mothers were not more likely to cuckold their partners if they had a different back color.

If natural selection indeed favors black-backed magpies in the north, the question still remains as to why all magpies are not black-backed. One possible explanation is that black and white feathers provide different levels of resistance to disease or parasites. However, the work that has been done in this area suggests that black feathers are more resistant to bacteria (Burtt and Ichida 2004). In fact, this has been suggested as an explanation for the tendency of plumage to be darker in hotter, more humid climates, where bacterial attack is likely to be greater (Burtt and Ichida 2004). So, while this provides an additional selective advantage for black-backed birds in the north, it does not explain the apparent advantage of white-backed birds in the south.

At this stage, the only other explanation is that white feathers are "cheaper" to produce. Some work on seabirds tends to support this idea. Indeed, a review by Tickell (2003) showed that, despite attempts to find evidence for adaptive advantages of white feathers, most of the results were not very convincing and probably, in general, feathers are white "by default." Furthermore, Bortolotti et al. (2006) showed that individual Red-legged Partridges (Alectoris rufa) in poor condition were unable to produce totally melanized feathers. These possibilities require further investigation.

\section{ACKNOWLEDGMents}

An enormous number of people have helped with field work in this project. In particular we thank A. Baker, C. Bartlett, G. Carini, B. Cook, K. Durrant, J. Fawcett, K. Goudkamp, J. Huey, D. Hurwood, A. Mather, M. Ponniah, A. Robinson, J. Smith, S. Smith, J. Somerville, and R. Woods. The project would not have been possible without the help and support of the landowners along Lambing Gully Road, particularly T. and L. Newton, C. and H. Tingay, C. and J. Newton, and the Lawrence family. We would especially like to thank T. and L. Newton for making their shearers' quarters available to us since 1996. This work was approved by the Victorian Flora and Fauna Permit 10004187, the Griffith University Ethics Committee (AES/16/04/AEC), and the Australian Bird and Bat Banding Scheme.

\section{Literature Cited}

Baker, A. M., P. B. Mather, And J. M. Hughes. 2000. Population genetic structure of Australian Magpies: Evidence for regional differences in juvenile dispersal behaviour. Heredity 85:167-176.

BAKer, M. C., AND J. T. Boylan. 1999. Singing behavior, mating associations and reproductive success in a population of hybridizing Lazuli and Indigo buntings. Condor 101:493-504.

Barrett, G., A. Silcocks, S. Barry, R. Cunningham, and R. Poulter. 2003. The New Atlas of Australian Birds. Royal Australasian Ornithologists Union, Melbourne.

Barton, N. H., AND G. M. Hewitr. 1985. Analysis of hybrid zones. Annual Review of Ecology and Systematics 16:113-148.

Bortolotti, G. R., J. Blas, J. J. Negro, And J. L. Tella. 2006. A complex plumage pattern as an honest signal. Animal Behaviour 72:423-430.

Bridle, J. R., C. I. Saldamando, W. Koning, and R. K. Butlin. 2006. Assortative preferences and discrimination by females against hybrid male song in the grasshoppers Chorthippus 
brunneus and Chorthippus jacobsi (Orthoptera: Acrididae). Journal of Evolutionary Biology 19:1248-1256.

Brodin, A., AND F. HaAs. 2009. Hybrid zone maintenance by nonadaptive mate choice. Evolutionary Ecology 23:17-29.

Burton, T. C., ANd A. A. Martin. 1976. Analysis of hybridization between black-backed and white-backed magpies in southeastern Australia. Emu 76:30-36.

BURTT, E. H., JR., AND J. M. ICHIDA. 2004. Gloger's rule, featherdegrading bacteria, and color variation among Song Sparrows. Condor 106:681-686.

CARrick, R. 1972. Population ecology of the Australian blackbacked magpie, Royal Penguin and Silver Gull. U.S. Department of Interior Wildlife Research Report 2:41-49.

DuRRANT, K. L., AND J. M. HugheS. 2005. Differing rates of extra-group paternity between two populations of the Australian Magpie (Gymnorhina tibicen). Behavioral Ecology and Sociobiology 57:536-545.

Durrant, K. L., AND J. M. Hughes. 2006. Are there correlates of male Australian Magpie Gymnorhina tibicen reproductive success in a population with high rates of extra-group paternity? Ibis 148:313-320.

Galeotti, P., D. Rubolini, P. O. Dunn, and M. Fasola. 2003. Colour polymorphism in birds: Causes and functions. Journal of Evolutionary Biology 16:635-646.

Griffith, S. C., I. P. F. Owens, and K. A. Thuman. 2002. Extra pair paternity in birds: A review of interspecific variation and adaptive function. Molecular Ecology 11:2195-2212.

Griffiths, R., S. DaAn, and C. Dijkstra. 1996. Sex identification in birds using two CHD genes. Proceedings of the Royal Society of London, Series B 263:1251-1256.

HaAs, F., J. KnAPE, And A. Brodin. 2010. Habitat preferences and positive assortative mating in an avian hybrid zone. Journal of Avian Biology 41:237-247.

Harrison, R. G. 1993. Hybrid Zones and the Evolutionary Process. Oxford University Press, Oxford, United Kingdom.

HewitT, G. M. 1988. Hybrid zones-Natural laboratories for evolutionary studies. Trends in Ecology \& Evolution 3:158-167.

Hughes, J. M. 1982. An explanation for the asymmetrical 'hybrid' zone between white-backed and black-backed magpies. Emu 82:50-53.

Hughes, J. M., A. M. Baker, G. De Zylva, and P. B. Mather. 2001. A phylogeographic analysis of southern and eastern populations of the Australian Magpie: Evidence for selection in maintenance of the distribution of two plumage morphs. Biological Journal of the Linnean Society 74:25-34.

Hughes, J. M., J. D. E. Hesp, R. Kallioinen, M. Kempster, C. L. Lange, K. E. Hedstrom, P. B. Mather, A. Robinson, and M. J. Wellbourn. 1996. Differences in social behaviour between populations of the Australian Magpie Gymnorhina tibicen. Emu 96:65-70.

Hughes, J. M., C. L. Lange, P. B. Mather, and A. Robinson. 2002. A comparison of fitness components among different plumage morphs of the Australian Magpie, Gymnorhina tibicen. Emu 102:331-338.

Hughes, J. M., P. B. Mather, A. Toon, J. Ma, I. Rowley, And E. Russell. 2003. High levels of extra-group paternity in a population of Australian Magpies Gymnorhina tibicen: Evidence from microsatellite analysis. Molecular Ecology 12:3441-3450.
JAMIESON, A. 1994. The effectiveness of using co-dominant polymorphic allelic series for (1) checking pedigrees and (2) distinguishing full-sib pair members. Animal Genetics 25 (Supplement 1):37-44.

Jiggins, C. D., And J. Mallet. 2000. Bimodal hybrid zones and speciation. Trends in Ecology \& Evolution 15:250-255.

Kallioinen, R. U. O., J. M. Hughes, and P. B. Mather. 1995. Significance of back colour in territorial interactions in the Australian Magpie. Australian Journal of Zoology 43:665-673.

Keller, L. F., AND D. M. WALLER. 2002. Inbreeding effects in wild populations. Trends in Ecology \& Evolution 17:230-241.

Marshall, T. C., J. Slate, L. E. B. Kruuk, and J. M. PemberTON. 1998. Statistical confidence for likelihood-based paternity inference in natural populations. Molecular Ecology 7:639-655.

Pearn, S. M., A. T. D. Bennett, and I. C. Cuthill. 2003. The role of ultraviolet-A reflectance and ultraviolet-A induced fluorescence in the appearance of Budgerigar plumage: Insights from spectrofluorometry and reflectance spectrophotometry. Proceedings of the Royal Society of London, Series B 270:859-865.

Price, T. D. 2008. Speciation in Birds. Roberts, Greenwood Village, Colorado.

Pryke, S. R., AND S. C. GRiffith. 2007. The relative role of male vs. female mate choice in maintaining assortative pairing among discrete colour morphs. Journal of Evolutionary Biology 20:1512-1521.

Queller, D. C., And K. F. Goodnight. 1989. Estimating relatedness using genetic-markers. Evolution 43:258-275.

Raymond, M., And F. Rousset. 1995. Population genetics software for exact tests and ecumenicism. Journal of Heredity 86:248-249.

Reudink, M. W., S. G. MeCh, ANd R. L. Curry. 2006. Extrapair paternity and mate choice in a chickadee hybrid zone. Behavioral Ecology 17:56-62.

Roulin, A. 2004. The evolution, maintenance and adaptive function of genetic colour polymorphism in birds. Biological Reviews 79:815-848.

SCHOdDE, R., AND I. J. Mason. 1999. The Directory of Australian Birds: Passerines. CSIRO Publishing, Melbourne.

TiCKELl, W. L. N. 2003. White plumage. Waterbirds 26:1-12.

Toon, A., J. Hughes, A. Baker, And P. Mather. 2003. Discordance between morphology and genetic structure among three plumage forms of the Australian Magpie. Emu 103:337-343.

Toon, A., P. B. Mather, A. M. Baker, K. L. Durrant, And J. M. Hughes. 2007. Pleistocene refugia in an arid landscape: Analysis of a widely distributed Australian passerine. Molecular Ecology 16:2525-2541.

Uy, J. A. C., AND A. C. Stein. 2007. Variable visual habitats may influence the spread of colourful plumage across an avian hybrid zone. Journal of Evolutionary Biology 20:1847-1858.

Veen, T., T. Borge, S. C. Griffith, G.-P. SÆtre, S. Bures, L. GusTAFSSON, AND B. C. SHELDON. 2001. Hybridization and adaptive mate choice in flycatchers. Nature 411:45-50.

Veltman, C. J., And R. Carrick. 1990. Male-biased dispersal in Australian Magpies. Animal Behaviour 40:190-192.

Associate Editor: J. Klicka 